\title{
Etiological Factors and Management of Vocal Fold Paralysis: Single Institution Study
}

\author{
Hassan Alassiry ${ }^{1,}$, Nasser Hassan ${ }^{2}$ \\ ${ }^{1}$ Department of Otorhinolaryngology, Head and Neck Surgery, King Abdulaziz University Hospital, Riyadh, Saudi Arabia \\ ${ }^{2}$ Department of Otorhinolaryngology, Head and Neck Surgery, King Abdulaziz Medical City, Riyadh, Saudi Arabia
}

Email address:

h.asiri99@gmail.com (H. Alassiry)

${ }^{*}$ Corresponding author

\section{To cite this article:}

Hassan Alassiry, Nasser Hassan. Etiological Factors and Management of Vocal Fold Paralysis: Single Institution Study. International Journal of Otorhinolaryngology. Vol. 4, No. 1, 2018, pp. 16-20. doi: 10.11648/j.ijo.20180401.15

Received: May 3, 2018; Accepted: May 22, 2018; Published: July 3, 2018

\begin{abstract}
Vocal fold paralysis is a sign of underlying diseases. However, etiologies of this problem are varied and changing from center to center and need more clarification. The aim of the study is to determine the etiological factors and management options of vocal fold paralysis among patients attended to the voice clinic center at King Abdul-Aziz Medical City. The medical records of 106 patients diagnosed with vocal fold paralysis were studied retrospectively. The following variables were recorded; age, gender, occupation, smoking, surgical history, radiation history, cause and type of vocal fold paralysis, associated risks, and management. Out of the 106 cases, 58 were males and 48 females with a ratio of 1.2:1. The age of the patients ranged from 6-92 years. Surgical trauma (iatrogenic) was the leading cause of vocal fold paralysis (45.3\%) followed by idiopathic (17.9\%), external neck trauma (13.2), Non-laryngeal malignancy $(6.6 \%)$, post upper respiratory tract infection and viral infection (5.7\%), TB and TB lymphadenitis (3.8\%), intubation (2.8\%), neurogenic (1.8\%) and thyroid mass $(1.8 \%)$. Total thyroidectomy was the most common surgical etiology of vocal fold paralysis (38.8\%). The most common etiology of vocal fold paralysis is surgery and most cases were total thyroidectomy. Otolaryngologists should be familiar with the etiology, incidence, evaluation, and management options of vocal fold paralysis to optimize patient care and avoid further complication. We recommend that all patients undergoing total thyroidectomy and surgeries related to the course of recurrent laryngeal nerves should have detailed voice assessment pre-and postoperatively.
\end{abstract}

Keywords: Vocal Fold Paralysis, Vocal Fold Paresis, Thyroidectomy

\section{Introduction}

Vocal fold paralysis is caused by abnormality in the laryngeal muscles due to partial or complete interruption of nerves which innervate that muscles. Those nerves are recurrent laryngeal nerve and superior laryngeal nerve. This disorder is caused by disruption, compression or inflammation of the nerves along its anatomic course. It can be caused by; post-surgical complication such as head, neck, thorax and cervical spine procedures. Other causes include neck or chest trauma, base of skull tumor, neck tumor, viral infections and as a complication of endotracheal intubation. Studies prove that unilateral vocal fold paralysis is predominantly idiopathic. However, there are many studies proves that surgical trauma is the most common cause of vocal fold paralysis. Vocal fold paralysis usually present with voice changes, airway problems, swallowing problem, and aspiration. [1-12]

The aim of the study is to determine the etiological factors and management options of vocal fold paralysis among patients attended to the voice clinic center at King AbdulAziz Medical City.

\section{Materials and Methods}

The study designated to be a retrospective cross-sectional study targeted all patients with vocal fold paralysis attended the voice clinic center at King Abdul-Aziz Medical City (KAMC) Riyadh, Saudi Arabia between January 2007 to December 2017. King Abdul-Aziz medical city is considered as a teaching and referral hospital in Riyadh which provide health services for National Guard employee and their 
dependents. After approval of institutional review board (RC16/115/R), all records belong to patients with voice disorder attended to the voice clinic center at King AbdulAziz Medical City during the study period were 999 records. Out of these records, 108 records belonged to vocal fold paralysis and 891 records belonged to other voice disorder. Among vocal fold paralysis and paresis records, there were 2 excluded records due to missed files and data. Finally, total number of 106 vocal fold records were studied retrospectively. All patients were subjected to history taking and examined by video-stroboscope using KAYPENTAX Rhino-laryngeal Stroboscope model (PLS 9100B). The following variables were being included in this study; age, gender, occupation, smoking, surgical history, radiation history, cause and type of vocal fold paralysis, associated risks, and management. The data was regained from Best care documentation system, patient's files and database of KAYPENTAX Rhino-laryngeal Stroboscope. The data transferred to excel sheet with all required variables.

Data was inputted from excel sheet and analyzed using SPSS 20 software for windows, for categorical variables calculated the proportion (\%) and for continues variables calculated means \pm standard deviation.

\section{Result}

We studied a total of 106 cases that fulfilled our inclusion criteria. Out of these, 58 were males and 48 were females with a ratio of 1.2:1. The age of the patients ranged from 692 years with average age of (49.77 \pm 20.71 years). For age groups, 41-60 years was the most common age group incidence of vocal fold paralysis $(36 \%, \mathrm{n}=39)$ followed by over 60 years $(31 \%, \mathrm{n}=33), 19-40$ years $(22.6 \%, \mathrm{n}=24)$, and $0-18$ years $(9.4 \%, \mathrm{n}=10)$. Regarding job classification, $(29.2 \%, \mathrm{n}=31)$ were house wife's, $(28.3 \%, \mathrm{n}=30)$ were retired, $(16 \%, \mathrm{n}=17)$ were students, $(8.5 \%, \mathrm{n}=9)$ were martial, $(4.7 \%, \mathrm{n}=5)$ were teacher, and only $(1.9 \%, \mathrm{n}=2)$ were nurses, the remained patients with different occupation were $(11.3 \%, \mathrm{n}=12)$ [Table1].

For type of vocal fold paralysis, left vocal fold is most vulnerable to paralysis $(52.8 \%, \mathrm{n}=56)$ than right vocal fold paralysis $(28.3 \%, \mathrm{n}=30)$, while bilateral vocal fold paralysis was $(15 \%, \mathrm{n}=16)$, left and right vocal fold paresis were 4 cases $(1.8 \%, \mathrm{n}=2$ for each side) [Table 2].

Regarding etiologies of vocal fold paralysis, Surgical trauma (iatrogenic) was a leading cause of vocal fold paralysis $(45.3 \%, \mathrm{n}=48)$ followed by idiopathic $(17.9 \%, \mathrm{n}=$ $19)$, external neck trauma $(13.2 \%, \mathrm{n}=14)$, Non-laryngeal malignancy $(6.6 \%, \mathrm{n}=7)$, post upper respiratory tract infection (URTI) and viral infection $(5.7 \%, \mathrm{n}=6)$, Tuberculosis (TB) and TB lymphadenitis $(3.8 \%, \mathrm{n}=4)$, intubation $(2.8 \%, \mathrm{n}=3)$, neurogenic $(1.8 \%, \mathrm{n}=2)$ and thyroid mass $(1.8 \%, \mathrm{n}=2)$ [Table 3 ].

Total thyroidectomy was the most common surgical etiology of vocal fold paralysis $(42.8 \%, \mathrm{n}=21)$ followed by cardiac surgery $(28.5 \%, \mathrm{n}=14)$, cervical spine fixation $(10.2 \%, \mathrm{n}=5)$, hemi thyroidectomy $(6.1 \%, \mathrm{n}=3)$, parathyroidectomy $(6.1 \%, \mathrm{n}=3)$, lymph node dissection $(2 \%, \mathrm{n}=1)$, aortic aneurism repair $(2 \%, \mathrm{n}=1)$ and posterior craniotomy $(2 \%, \mathrm{n}=1)$ [Table 4 ].

For Non-laryngeal malignancy etiologies of vocal fold paralysis, lung cancer was the most common $(28.6 \%, \mathrm{n}=2)$ followed by esophageal cancer $(14.3 \% \mathrm{n}=1)$, adenocarcinoma of unknown origin $(14.3 \% \mathrm{n}=1)$, Jugulotympanic paraganglioma $(14.3 \% \mathrm{n}=1)$, lymphoma $(14.3 \% \mathrm{n}=1)$ and malignant otitis externa $(14.3 \% \mathrm{n}=1)$ [Table 5].

For associated factors of vocal fold paralysis, Gastroesophageal reflux disease (GERD) was the most common associated factor $(40.6 \%, \mathrm{n}=43)$ followed by diabetes mellitus $(27.4 \%, \mathrm{n}=29)$, hypertension $(26.4 \%, \mathrm{n}=$ $28)$, history of radiation exposure $(17 \%, \mathrm{n}=18)$, smoking $(16 \%, \mathrm{n}=17)$, bronchial asthma $(13.2 \%, \mathrm{n}=14)$, and other associated diseases such as Parkinson, ischemic heart disease, stroke, gastric lymphoma, esophageal diverticulum, chronic obstructive pulmonary disease (COPD), systemic lupus erythematous, contact granuloma and facial nerve palsy were $(26 \%, \mathrm{n}=28)$, patients had more than one factor at the same time [Table 6].

Management of vocal fold paralysis include different modalities, most of the cases were managed conservatively $(78.3 \%, \mathrm{n}=83)$, while 10 cases $(9.4 \%)$ underwent surgery only and 13 cases (12.3\%) have both surgery and conservative therapy. Conservative management include: voice hygiene advice $(58.6 \%, \mathrm{n}=62)$, voice therapy $(23.6 \%$, $\mathrm{n}=25)$, neuro-vitamins $(13.2 \%, \mathrm{n}=14)$. Among these conservative options, 50 patients $(60.2 \%)$ had only one conservative option, 32 patients $(38.5 \%)$ had 2 conservative options and only 1 patient (1.1\%) had 3 conservative options. Surgical management include: medialization injection with calcium hydroxylapatite $(12.3 \%, \mathrm{n}=13)$, thyroplasty for unilateral vocal fold paralysis $(3.8 \%, \mathrm{n}=4)$ and cordotomy for bilateral vocal fold paralysis $(5.7 \%, \mathrm{n}=6)$ [Table7].

Table 1. Demographic data of vocal fold paralysis at KAMC 2007-2017.

\begin{tabular}{lll}
\hline Demographic data & n (\%) \\
\hline \multirow{3}{*}{ Age of patient mean $=49.77 \pm$} & $0-18$ & $10(9.4 \%)$ \\
20.71 years & $19-40$ & $24(22.6 \%)$ \\
& $41-60$ & $39(36 \%)$ \\
Gender & $>60$ & $33(31 \%)$ \\
& Male & $58(54.7 \%)$ \\
& Female & $48(45.3 \%)$ \\
& Student & $17(16.0 \%)$ \\
Occupation & Teacher & $5(4.7 \%)$ \\
& House wife & $31(29.2 \%)$ \\
& Martial & $9(8.5 \%)$ \\
& Retired & $30(28.3 \%)$ \\
& Nurse & $2(1.9 \%)$ \\
& Other & $12(11.3 \%)$ \\
\hline
\end{tabular}

Table 2. Types of vocal fold paralysis at KAMC 2007-2017.

\begin{tabular}{ll}
\hline Types & n (\%) \\
\hline Bilateral vocal folds paralysis & $16(15 \%)$ \\
Left vocal fold paralysis & $56(52.8 \%)$ \\
Right vocal fold paralysis & $30(28.3 \%)$ \\
Left vocal fold paresis & $2(1.8 \%)$ \\
Right vocal fold paresis & $2(1.8 \%)$ \\
Total & 106 \\
\hline
\end{tabular}


Table 3. Etiologies of vocal fold paralysis at KAMC 2007-2017.

\begin{tabular}{ll}
\hline Causes & $\mathbf{n}(\mathbf{\%})$ \\
\hline Surgical trauma & $49(46.2 \%)$ \\
Non-laryngeal malignancy & $7(6.6 \%)$ \\
External neck trauma & $14(13.2 \%)$ \\
Idiopathic & $19(17.9 \%)$ \\
Neurogenic & $2(1.8 \%)$ \\
Intubation & $3(2.8 \%)$ \\
Post URTI and viral infection & $6(5.7 \%)$ \\
Thyroid mass & $2(1.9 \%)$ \\
TB and TB lymphadenitis & $4(3.8 \%)$ \\
Total & 106 \\
\hline
\end{tabular}

Table 4. Surgical causes of vocal fold paralysis at KAMC 2007-2017.

\begin{tabular}{ll}
\hline Type of surgery & n (\%) \\
\hline Total thyroidectomy & $21(42.8 \%)$ \\
Hemi thyroidectomy & $3(6.1 \%)$ \\
Parathyroidectomy & $3(6.1 \%)$ \\
Cardiac surgery & $14(28.5 \%)$ \\
Cervical spine fixation & $5(10.2 \%)$ \\
Lymph node excision & $1(2.0 \%)$ \\
Aortic aneurism repair & $1(2.0 \%)$ \\
Posterior craniotomy & $1(2.0 \%)$ \\
Total & 49 \\
\hline
\end{tabular}

Table 5. Non-laryngeal malignancy causes of vocal fold paralysis at KAMC 2007-2017.

\begin{tabular}{ll}
\hline Non-laryngeal malignancy cause & $\mathbf{n}(\mathbf{\%})$ \\
\hline Lung cancer & $2(28.6 \%)$ \\
Malignant otitis externa & $1(14.3 \%)$ \\
Esophageal cancer & $1(14.3 \%)$ \\
Adenocarcinoma of unknown origin & $1(14.3 \%)$ \\
Jugulotympanic paraganglioma & $1(14.3 \%)$ \\
Lymphoma & $1(14.3 \%)$ \\
Total & 7 \\
\hline
\end{tabular}

Table 6. Associated factors of vocal fold paralysis at KAMC 2007-2017.

\begin{tabular}{ll}
\hline Associated factors & n (\%) \\
\hline Smoking & $17(16 \%)(14$ males, 3 females $)$ \\
GERD & $43(40.6 \%)$ \\
Diabetes mellitus & $29(27.4 \%)$ \\
Hypertension & $28(26.4 \%)$ \\
Bronchial asthma & $14(13.2 \%)$ \\
Radiation & $18(17 \%)$ \\
others & $28(26 \%)$ \\
\hline
\end{tabular}

Table 7. Management of vocal fold paralysis at KAMC 2007-2017.

\begin{tabular}{ll}
\hline Management & $\mathbf{n}(\mathbf{\%})$ \\
\hline Conservative only & $83(78.3 \%)$ \\
Surgery only & $10(9.4 \%)$ \\
Conservative and surgery & $13(12.3 \%)$ \\
Total & 106 \\
Conservative management types: & \\
1. Voice hygiene & $62(58.6 \%)$ \\
2. Voice therapy & $25(23.6 \%)$ \\
3. Neuro-vitamins & $14(13.2 \%)$ \\
Surgery management types: & \\
1. Medialization injection & $13(12.3 \%)$ \\
2. Thyroplasty & $4(3.8 \%)$ \\
3. Cordotomy & $6(5.7 \%)$ \\
\hline
\end{tabular}

\section{Discussion}

Vocal fold paralysis is a common problem in otolaryngology practice.

For age and occupation of the patients in this study, we had patients with age ranging from 6 years to 92 years with average age (49.77 \pm 20.71 years). Vocal fold paralysis incidence found to be increased with age, rising and peaked in the fifth and sixth decade, this finding is in accordance with literature; Yumoto et al., who found that the incidence of vocal fold paralysis in the fourth decade is rapidly raised and peaked in the sixth decade. Moreover, Gandhi $\mathrm{S}$ et al. reported that unilateral vocal fold paralysis peaked in the fourth and fifth decade. $[13,14]$ Vocal fold paralysis found to be not related to the occupation of the patients; this finding was emphasized by Srivastava $\mathrm{S}$ et al. [15]

Regarding male to female ratio $(1.2: 1)$, this finding is consistent with finding of Gandhi $\mathrm{S}$ et al. in which male to female ratio was 1.82: 1. Myssiorek D. has similar findings. On the contrary, Rosenthal et al. reported that female to male ratio was (1.43:1) for those who diagnosed with vocal fold paralysis. [1, 13, 16] The reason of male to female ratio discrepancy in literature is still not clear, we think that it is related to the type of centers and scope of the patients.

Left-sided vocal fold paralysis was diagnosed in more than half $(52.8 \%)$ of the patients, while right vocal fold paralysis was diagnosed in $(28.3 \%)$ of the patients. This finding is in agreement with literature. In the study done at Gartnavel General Hospital-Scotland to identify the etiology of unilateral vocal fold paralysis between 1997 to 2001; 77 patients were assessed, $83 \%$ of them had vocal fold paralysis in the left side and $17 \%$ had right vocal fold paralysis. Furthermore, similar findings were observed in other studies. [13-18] This support the fact that the left recurrent laryngeal nerve is more vulnerable to be injured due to its longer anatomical course through the chest.

As far as the etiologies are concerned, surgical trauma (iatrogenic) found to be the main cause of vocal fold paralysis in almost half of the patients $(45.3 \%)$. This finding is consistent with literature; Takano $\mathrm{S}$ et al. reported that the incidence of post-surgical (iatrogenic) vocal fold paralysis was $(58.5 \%)$ and non-surgical etiology was (41.5\%). Other studies revealed that the incidence of iatrogenic vocal fold paralysis ranged from $11 \%$ to $66 \%$. [18-28]

Among surgical trauma causes of vocal fold paralysis, total thyroidectomy was the most common reported procedure $(38.8 \%)$. Takano $\mathrm{S}$ et al proved same finding with total number of 106 cases $(22.7 \%)$ out of 466 cases. Previous studies reported that the rate of vocal fold paralysis post thyroid surgery ranged from 7-50.9\%. [18-20, 23, 28]

In addition to total thyroidectomy, we reported that cardiac surgery, cervical spine fixation, hemithyroidectomy, parathyroidectomy, lymph node dissection, aortic aneurysm repair and posterior craniotomy as surgical etiologies for vocal fold paralysis. These causes were found in previous studies with different range of incidence. [3, 29-34]

Idiopathic cause of vocal fold paralysis was found in 19 
cases (17.9\%). This finding is in conjugation with literature; $\mathrm{Al}-\mathrm{Khtoum} \mathrm{N}$ et al. found that the incidence of idiopathic vocal fold paralysis was $18.9 \%$. [18] On the contrary, Gandhi $\mathrm{S}$ et al. reported that the predominant etiological factor of vocal fold paralysis found to be idiopathic (49.1\%). [13]

Other etiologies for vocal fold paralysis reported in our study include external neck trauma, non-laryngeal malignancy, post URTI, TB and TB lymphadenitis, endotracheal intubation, thyroid mass and neurogenic origin. Many previous studies found same etiologies in addition to other etiology such as sarcoidosis with different range of incidence. [13, 18, 35-37]

Non-laryngeal malignancy has been reported in seven cases $(6.6 \%)$ of this study, 2 cases $(28.6 \%)$ were due to lung cancer and the remained 5 cases were esophageal cancer, adenocarcinoma of unknown origin, jugulotympanic paraganglioma, lymphoma and malignant otitis externa. Similar finding was reported by Al-Khtoum $\mathrm{N}$ et al study, they found that $7.5 \%$ of non-laryngeal malignancy were responsible for unilateral vocal fold paralysis. Furthermore, many previous studies found the most common nonlaryngeal malignancy causing vocal fold paralysis was lung cancer. $[1,14,18,19]$

Gastroesophageal reflux disease found to be predominantlly associated factor for vocal fold paralysis with total number of 43 cases $(40.6 \%)$ followed by diabetes mellitus and hypertension with 29 cases (27.4\%) and 28 cases $(26.4 \%)$ respectively.

Radiation exposure found in 18 cases of this study. However, all cases with vocal fold paralysis and exposed to radiation had concomitant other cause of vocal fold paralysis and documented as the main cause of the vocal fold paralysis, 17 of the cases had total thyroidectomy followed by vocal fold paralysis and 1 case with jugulotympanic paraganglioma developed vocal fold paralysis before radiation exposure.

The discrepancy in the literature regarding the etiology of vocal fold paralysis may be due to the scope of diseases treated in each center.

Management options of vocal fold paralysis in our study were conservative, surgically or both. Conservative management was the major treatment option for our patients with total number of 83 cases $(78.3 \%)$ and included one or more of the following: voice hygiene, voice therapy, and neuro-vitamins. Surgical options were done for 10 cases $(9.4 \%)$ either by medialization injection with calcium hydroxylapatite voice gel, thyroplasty (for unilateral vocal fold paralysis) or cordotomy (for bilateral vocal fold paralysis). Moreover, there were 13 cases $(12.3 \%)$ had both conservative and surgical treatment. Jiang $\mathrm{Y}$ et al. classified treatments methods as medication (glucocorticoids, neurotrophic medicines, and vasodilators); acupuncture and moxibustion, ultrashort wave therapy, voice therapy, medialization injection and re-innervation methods. [38] Different modalities of management can be explained by different facilities and experts in each center. [39]

\section{Conclusion}

The most common etiology of vocal fold paralysis is surgery and majority of the cases were total thyroidectomy. Otolaryngologists should be familiar with the etiology, incidence, evaluation, and management options of vocal fold paralysis to optimize patient care and avoid further complication. We recommend that all patients undergoing total thyroidectomy should have routine laryngoscopy preand postoperatively. In tertiary hospital, it is highly needed to have expert phono-surgeon or laryngologist who can optimize management of such cases.

\section{References}

[1] Rosenthal LH, Benninger MS, Deeb RH. Vocal fold immobility; a longitudinal analysis of etiology over 20 years. Laryngoscope. 2007 Oct; 117 (10):1864-70.

[2] Sulica L. The natural history of idiopathic unilateral vocal fold paralysis: evidence and problems .Laryngoscope. $2008 \mathrm{Jul}$; 118 (7):1303-7.

[3] Ramadan HH, Wax MK, Avery S. Outcome and changing cause of unilateral vocal cord paralysis. OTO-HNS. $1998 \mathrm{Feb}$; 118 (2):199-202.

[4] Weisberg NK, Spengler DM, Netterville JL. Stretch-induced nerve injury as a cause of paralysis secondary to the anterior cervical approach. OTO-HNS. 1997 Mar; 116 (3):317-26.

[5] Netterville JL, Koriwchak MJ, Winkle M, Courey MS, Ossoff $\mathrm{RH}$. Vocal fold paralysis following the anterior approach to the cervical spine. AOR. $1996 \mathrm{Feb} ; 105$ (2):85-91.

[6] Sugarbaker DJ, Jaklitsch MT, Bueno R, Richards W, Lukanich J, Mentzer SJ, et al. Prevention, early detection, and management of complications after 328 consecutive extrapleural pneumonectomies. JTCVS. 2004 Jul; 128 (1):138-46.

[7] Filaire M, Mom T, Laurent S, Harouna Y, Naamee A, Vallet L, et al. Vocal cord dysfunction after left lung resection for cancer. EJCTS. 2001 Oct; 20 (4):705-11.

[8] Dimarakis I, Protopapas AD. Vocal cord palsy as a complication of adult cardiac surgery: surgical correlations and analysis. EJCTS. 2004 Oct; 26 (4):773-5.

[9] Gockel I, Kneist W, Keilmann A, Junginger T. Recurrent laryngeal nerve paralysis (RLNP) following esophagectomy for carcinoma. EJSO. 2005 Apr; 31 (3):277-81.

[10] Netterville JL, Jackson CG, Miller FR, Wanamaker JR, Glasscock ME. Vagal paraganglioma: a review of 46 patients treated during a 20-year period. Archotol. 199 80ct; 124 (10):1133-40.

[11] Zambudio AR, Rodriguez J, Riquelme J, Soria T, Canteras M, Parrilla P. Prospective study of postoperative complications after total thyroidectomy for multinodular goiters by surgeons with experience in endocrine surgery. Ann Surg. 2004 Jul; 240 (1):18-25

[12] Steurer M, Passler C, Denk DM, Schneider B, Niederle B, Bigenzahn W. Advantages of recurrent laryngeal nerve identification in thyroidectomy and parathyroidectomy and the importance of preoperative and postoperative laryngoscopic examination in more than 1000 nerves at risk. Laryngoscope. 2002 Jan; 112 (1):124-33. 
[13] Gandhi S, Rai S, Bhowmick N. Etiological profile of unilateral vocal fold paralysis: A single institutional experience over 10 years. JLV. 2015; 4 (2):58-62.

[14] Yumoto E, Minoda R, Hyodo M, Yamagata T. Causes of recurrent laryngeal nerve paralysis. Auris Nasus Larynx $2002 ; 29: 41-5$.

[15] Srivastava RN et al. A clinical study of laryngeal paralysis. Indian J otolaryngol 1979; 31:41.

[16] Myssiorek D. Recurrent laryngeal nerve paralysis: Anatomy and etiology. Otolaryngol Clin North Am 2004; 37:25-44.

[17] Loughran S, Alves C, MacGregor FB. Current aetiology of unilateral vocal fold paralysis in a teaching hospital in the West of Scotland. JLO. 2002 Nov; 116 (11):907-10.

[18] Al-Khtoum N, Shawakfeh N, Al-Safadi E, Al-Momani O, Hamasha K. Acquired unilateral vocal fold paralysis: retrospective analysis of a single institutional experience. NAJMS. 2013 Dec; 5 (12):699-702.

[19] Benninger MS, Gillen JB, Altman JS. Changing etiology of vocal fold immobility. Laryngoscope. 1998 Sep; 108 (9):134650 .

[20] Takano S, Nito T, Tamaruya N, Kimura M, Tayama N. Single institutional analysis of trends over 45 years in etiology of vocal fold paralysis. Auris Nasus Larynx. 2012 Dec; 39 (6):597-600.

[21] Maisel RH, Ogura JH. Evaluation and treatment of vocal cord paralysis. Laryngoscope 1974; 84:302-16.

[22] Parnell FW, Brandenburg JH. Vocal cord paralysis. A review of 100 cases. Laryngoscope 1970; 80:1036-45.

[23] Tucker HM. Vocal cord paralysis-1979: Etiology and management. Laryngoscope 1980; 90:585-90.

[24] Barondess JA, Pompei P, Schley WS. A study of vocal cord palsy. Trans Am Clin Climatal Assoc 1985; 97:141-8.

[25] Titche LL. Causes of recurrent laryngeal nerve paralysis. Arch Otolaryngol 1976; 102:259-61.

[26] Terris DJ, Arnstein DP, Nguyen HH. Contemporary evaluation of unilateral vocal cord paralysis. Otolaryngol Head Neck Surg 1992; 107:84-90.

[27] Holinger LD, Holinger PC, Holinger PH. Etiology of bilateral abductor vocal cord paralysis: A review of 389 cases. Ann Otol Rhino1 Laryngol 1976; 85:428-36.

[28] Benninger MS, Crumley RL, Ford CN, Gould WJ, Hanson
DG, Ossoff RH, et al. Evaluation and treatment of unilateral paralyzed vocal fold. Otolaryngol Head Neck Surg 1997; 111:497-508.

[29] Hamdan AL, Moukarbela RV, Farhata F, Obeidb M. Vocal fold paralysis after open heart surgery. Eur J Cardiothoracic Surg 2002; 21:671-4.

[30] Gelpke H, Grieder F, Decurtins M, et al. Recurrent laryngeal nerve monitoring during esophagectomy and mediastinal lymph node dissection. World J Surg 2010; 34:2379-82. 10.1007/s00268-010-0692-0.

[31] Ishimoto $\mathrm{S}$, Ito $\mathrm{K}$, Toyama $\mathrm{M}$, et al. Vocal cord paralysis after surgery for thoracic aortic aneurysm. Chest 2002; 121:19111915.

[32] Joliat G-R, Guarnero V, Demartines N, Schweizer V, Matter M. Recurrent laryngeal nerve injury after thyroid and parathyroid surgery: Incidence and postoperative evolution assessment. Fröhlich. E, ed. Medicine. 2017; 96 (17):e6674. doi:10.1097/MD.0000000000006674.

[33] Jung A, Schramm J, Lehnerdt K, Herberhold C. Recurrent laryngeal nerve palsy during anterior cervical spine surgery: A prospective study. J Neurosurg Spine 2005; 2:123-7.

[34] Kahraman S, Sirin S, Erdogan E, Atabey C, Daneyemez M, Gonul E. Is dysphonia permanent or temporary after anterior cervical approach? Eur Spine J 2007; 16:2092-5.

[35] Holley HS, Gildea JE. Vocal Cord Paralysis After Tracheal Intubation. JAMA. 1971; 215 (2):281-284. doi:10.1001/jama.1971.03180150063013.

[36] Ueha R, Nito T, Goto T, Sato T, Ushiku T, Yamasoba T. Bilateral vocal cord immobility resulting from cytomegalovirus pharyngitis: A case report. J Infect Chemother. 2018 Feb; 24 (2):142-146. doi: 10.1016/j.jiac.2017.09.007. Epub 2017 Oct 17.

[37] Hintze JM, Gnagi SH, Lott DG. Sarcoidosis Presenting as Bilateral Vocal Fold Immobility. J Voice. 2018 May; 32 (3):359-362. doi: 10.1016/j.jvoice.2017.05.017. Epub 2017 Jul 3.

[38] Jiang Y, Gao B, Zhang X, et al. Prevention and treatment of recurrent laryngeal nerve injury in thyroid surgery. International Journal of Clinical and Experimental Medicine. 2014; 7 (1):101-107.

[39] Silva Merea V1, Husain S2, Sulica L3. Medialization Laryngoplasty After Injection Augmentation. J Voice. 2018 Mar; 32 (2):249-255. doi: 10.1016/j.jvoice.2017.05.007. Epub 2017 Jul 3. 